\title{
Institutions, Policies and Economic Development
}

\author{
Grzegorz W. Kolodko*
}

February 2006

\begin{abstract}
Institutions are not only created and built, but also, and especially, need to be learnt. It is a process which takes place in all economies, but acquires a special importance in less advanced countries. Not only theoretical arguments, but also the practical experience over the past 15 years demonstrates that faster economic growth, and hence also more broadly, socioeconomic development, is attained by those countries which take greater care to foster the institutional reinforcement of market economy. However, progress in market-economy institution building is not in itself sufficient to ensure sustained growth. Another indispensable component is an appropriately designed and implemented economic policy which must not confuse the means with the aims.
\end{abstract}

Keywords: institutions, economic policy, transition, growth, development, globalization JEL classification: A11, E6, F02, F43, H11, I38, N1, O17

Copyright @ C UNU-WIDER 2006

*Transformation, Integration and Globalization Economic Research at the Kozminski School of Business, Warsaw.

This study is a revised version of the paper presented at the 17-18 June 2005 UNU-WIDER anniversary conference, 'WIDER Thinking Ahead: The Future of Development Economics', directed by George Mavrotas and Anthony Shorrocks.

UNU-WIDER gratefully acknowledges the financial contributions to the research programme by the governments of Denmark (Royal Ministry of Foreign Affairs), Finland (Ministry for Foreign Affairs), Norway (Royal Ministry of Foreign Affairs), Sweden (Swedish International Development Cooperation Agency_Sida) and the United Kingdom (Department for International Development). 
The World Institute for Development Economics Research (WIDER) was established by the United Nations University (UNU) as its first research and training centre and started work in Helsinki, Finland in 1985. The Institute undertakes applied research and policy analysis on structural changes affecting the developing and transitional economies, provides a forum for the advocacy of policies leading to robust, equitable and environmentally sustainable growth, and promotes capacity strengthening and training in the field of economic and social policy making. Work is carried out by staff researchers and visiting scholars in Helsinki and through networks of collaborating scholars and institutions around the world. www.wider.unu.edu publications@wider.unu.edu

UNU World Institute for Development Economics Research (UNU-WIDER)

Katajanokanlaituri 6 B, 00160 Helsinki, Finland

Camera-ready typescript prepared by Lorraine Telfer-Taivainen at UNU-WIDER

The views expressed in this publication are those of the author(s). Publication does not imply endorsement by the Institute or the United Nations University, nor by the programme/project sponsors, of any of the views expressed. 


\section{Introduction}

When it seems that everything or nearly everything has been said about the prerequisites and prospects of economic growth 1 it is worthwhile to revisit certain aspects of this phenomenon, which is of vital importance for the functioning and development of society. All the more so in view of the conflicting opinions on the matter: while some authors appear quite optimistic, hopefully not without justification, others tend towards pessimism, on rational grounds, too. 2 We are especially interested in growth factors and the causes of disparities between the potential and actual growth rates. In this connection, I wish to take up some issues pertaining to the interaction between, on the one hand, the structure and functioning of market economy institutions and, on the other, the policy followed within their framework and the efficiency of its instruments, focusing on the implications for long-term output dynamics. A great many reflections spring to mind in this context, at least some of which merit a closer look

Particularly, the investigation focuses on Poland. The case of Poland-the largest economy (the GDP of almost PPP $\$ 500$ billion in 2006) and most populated (38.2 million inhabitants) country in East Central Europe-is remarkable, yet the progress accomplished over last 15 years has been quite different in particular periods of time. And the case is still more interesting since Poland was a pioneer of transition to a market system among the former socialist centrally planned economies. No doubt, the Polish lessons are relevant not only for countries in the region, but for developing economies generally. 3 So, it is indeed illuminating to consider the prevailing economic and political conditions in Poland and East Central Europe for other emerging market economies and developing countries.

\section{Inevitable growth}

Above a certain level of maturity, economic mechanisms make long-term growth inevitable. The exceptions only prove the rule here, although the most persistent of these (nowadays mainly in some poor countries of sub-Saharan Africa), inflict great hardships upon the affected populations. The main reason behind the self-sustaining nature of growth is an objective desire on the part of producers to maximize profits and on the part of consumers to lead a better life. These goals are unattainable in the long run through the redistribution of a stagnant national income. The increase of manufacturers' profits, along with the improvement of the living standards, can only be driven by output growth.

\footnotetext{
1 See Helpman (2004); Rodrik (2005).

2 See Kolodko (2002); Sachs (2005); Podkaminer (2004)

3 See Kolodko (2004).
} 
Importantly, the politicians in power should actively seek to promote growth, or else their authority will wither away in the long run, at least in democratic countries. In nondemocratic ones, too, for even though it may be possible to stay in power longer in their environment, the ultimate fall becomes all the more dramatic and in the ensuing interregnum, the country is plunged into even greater chaos, with disastrous consequences for the level of economic activity, as we have witnessed recently in Zaire, Haiti or Venezuela.

Seen against this background, the experience of post-socialist transforming economies has been relatively encouraging. It shows that power can be gained (or lost, as has been the case in Poland) at constitutionally prescribed intervals through a democratic election, but also (as in Georgia in late 2003 and early 2004) as a result of a strong political pressure exerted by rioters in the streets (who, interestingly, won the support of the democratic part of the international community). Even so, it is possible that a government may really thirst for economic growth and yet fail to pursue an effective policy to attain this goal.

Another inauspicious scenario can materialize when the economic policy - in its fiscal, monetary, industrial and trade dimensions-followed by a government or by an independent central bank is intentionally oriented towards other top-priority goals, to the detriment of economic dynamics, which is seen as a matter of secondary importance only. Such a policy may sometimes be justified, in particular, when maintaining or restoring financial and economic equilibrium is at stake. But on other occasions, as was demonstrated in Poland in 1998-2001, and even more dramatically in 1989-92, such a policy confuses the instruments of economic policy with its aims. 4 To be sure, and quite predictably, the proponents and advocates of such policies are of quite a different opinion (IMF 2000: 127-201).

Incidentally, the question of identifying means and ends in the context of development processes deserves further serious debate. From a purely economic standpoint, it should be obvious that the goal is socioeconomic development, part of which is economic growth per se. Such categories and processes as budget, inflation, privatization, rates of exchange, interest rates, taxes etc. are merely instruments facilitating the attainment of this supreme goal. Confusing these two things in economic policy is quite costly, as the Poles have had a chance to learn over the past 15 years, although, luckily, on a smaller scale than some other countries in the region. In a broader context, bearing in mind that freedom and democracy are autonomous values, dilemmas arise around the question of what should be subservient and subordinate to what. Sen (2000: 10) appears to be free from doubt on that score as he declares that 'freedoms are not only the primary ends of development, they are also among its principal means'. This is the right approach, for it emphasizes the positive feedback between freedom and development. The problem is

4 Kolodko (2000a); Stiglitz (2002). 
that this synergy only manifests itself in the long-term or even very long-term perspective. Once again, one needs to be very patient. However, as the biological clock is ticking away, not everyone will be able to enjoy the fruits of their patience.

Is it then possible, or, differently put, is it worthwhile to subordinate freedom and democracy to the requirements of an efficient economic policy and rapid output growth, which brings about an outcome of vast importance: an improvement in the living standards? This seems to be the prevailing approach, for instance, in China and Vietnam, where sensible development policies have been pursued for many years, in the context of rather limited democratic arrangements, but not so in Uzbekistan or Turkmenistan, where such policies have been lacking. Or is it, perhaps, better to cherish freedom and democracy, even if they stand in the way of implementing an effective progrowth policy? This has been the case in Poland, among other places, where the institutional weakness of a young political democracy and civil society hampers the pursuit of a sensible pro-growth policy and affects the functionality of the painstakingly constructed institutions of market economy.

I believe that it is not enough to win majority support for one's views: these need to be the right views in the first place. But the reverse is also true: in a democracy, being right is not enough — one needs majority support besides. And political practice shows unequivocally that what is right on substantive grounds may not come across to the majority and win its understanding and approval. Not least because an influential, opinion-making minority can make use of various democratic institutions, such as the media, to impose their priorities on others. This is the paradoxical case of a democratically endorsed, yet erroneous policy. Such a policy has to be continued until the majority comes round to the right way of thinking or, conversely, those who are right become a majority. Once again, this requires not only knowledge and culture, but also time and patience. And the latter is likely to run out with some people or at certain times.

The main problems of interest for us are the rate of economic growth, the structure of the increments of global output and their absorption over time, as well as the distribution of growth effects among various social, occupational and income groups, and their allocation to various types of goals. When analyzing these problems, one must not abstract away from the regional aspect of income creation and distribution. The policy of GDP (re)distribution in time and space (construed in social as well as geographical terms) is more likely to stir up controversy than the issue of output dynamics itself. In some cases more social and economic problems arise in times of relatively faster growth, because it is accompanied by increased redistribution. As a result, grievances about perceived inequitable division of the fruits of growth are more acute than at a time of weaker economic dynamics. 
Undoubtedly, this syndrome can be observed in present day Poland, as the rate of growth has accelerated again. For even if GDP increases at 4-5 per cent a year, a significant part of society (possibly even a majority) still fails to benefit from this growth. Worse still, there are groups of households and entrepreneurs who experience a continuing, painful drop in real incomes. For them, the growth of output, which has already attained substantial proportions, signifies a 'loss'. This generates resentment which not only prevents reaching the level of social contentment that would be attainable assuming a different distribution of income, but also affects growth in the long run. 5 Thus an inequitable distribution of income (or, more precisely, of the effects of its real increase) is harmful not only from a social point of view, but also for purely pragmatic reasons, for such a policy hinders efficiency and growth, so after a while it turns against its former beneficiaries. Interestingly, the latter often fail to understand this, also in Poland, as is attested to by the never-ending controversies over tax rates applicable to the relatively richer sectors of society.

\section{Expectations and realities}

Global experience shows that the expected growth rate is usually higher than that actually achieved. It is enough just to compare the annually published International Monetary Fund economic outlooks and their forecast, which quite often already after half a year is downward revised and less optimistic than at the earlier date. To be sure, there had been a lot of exaggerated optimistic expectations at the onset of postsocialist transition in Poland, Russia and elsewhere among the transition economies. 6 In Poland the transitional recession-according to the government plans, approved by the IMFwas supposed not to exceed 3.2 per cent and last no more than one year. Indeed, it lasted three years (from mid 1989 until mid 1992) and the GDP shrunk by almost 20 per cent.7

This gives rise afterwards to never-ending scholarly and political debates, as well as increasing social frustration. It almost looks like an inherent feature, shared not only by politicians (who are especially prone to exhibit it) and economists (that is to say, most of them), but also by entire societies at low to medium levels of economic development. The reason may be that politicians and economists tend to persuade societies ex ante they can attain certain goals, and then blame ex post their failure to achieve it, alternately, on others (politicians and economists) or acts of God (such as too high or too low oil prices, the Russian or Argentinean crisis, too high or too low exchange rates, etc.). Only the most highly developed countries have been cured from this peculiar malaise of excessive optimism, although, perhaps, not forever, not everywhere and not fully.

\footnotetext{
5 Tanzi et al. (1999); Kolodko (2000b).

6 Kolodko (2002).

7 EBRD (1996); Kolodko (1993).
} 
Thus nearly everyone expects a higher growth rate than they deserve in view of their perseverance (or lack thereof), organization and management quality, institutional (im)maturity and foresight. In particular, this symptom has been observed, from the very outset, in post-socialist transforming economies, where expectations about the scale and rate of production and consumption growth far exceeded the rather disappointing, as it was later to turn out, reality. This also applies to Poland, even though its aggregate growth over the past 15 years of transformation-for all its enormous variability over time-has been larger than in any other country in Central and Eastern Europe (CEE) and the Commonwealth of Independent States (CIS); see Figure 1. Apparently only China has avoided this kind of disillusionment, as it manages to have doubled its GDP every decade thanks to an incredibly rapid growth, and discontentment may only stem from the distribution of the effects of this growth and certain extra economic factors affecting the ways Chinese society functions (Lin et al. 2003).

Figure 1: GDP growth in China, Poland, Russia and Ukraine in 1990-2003

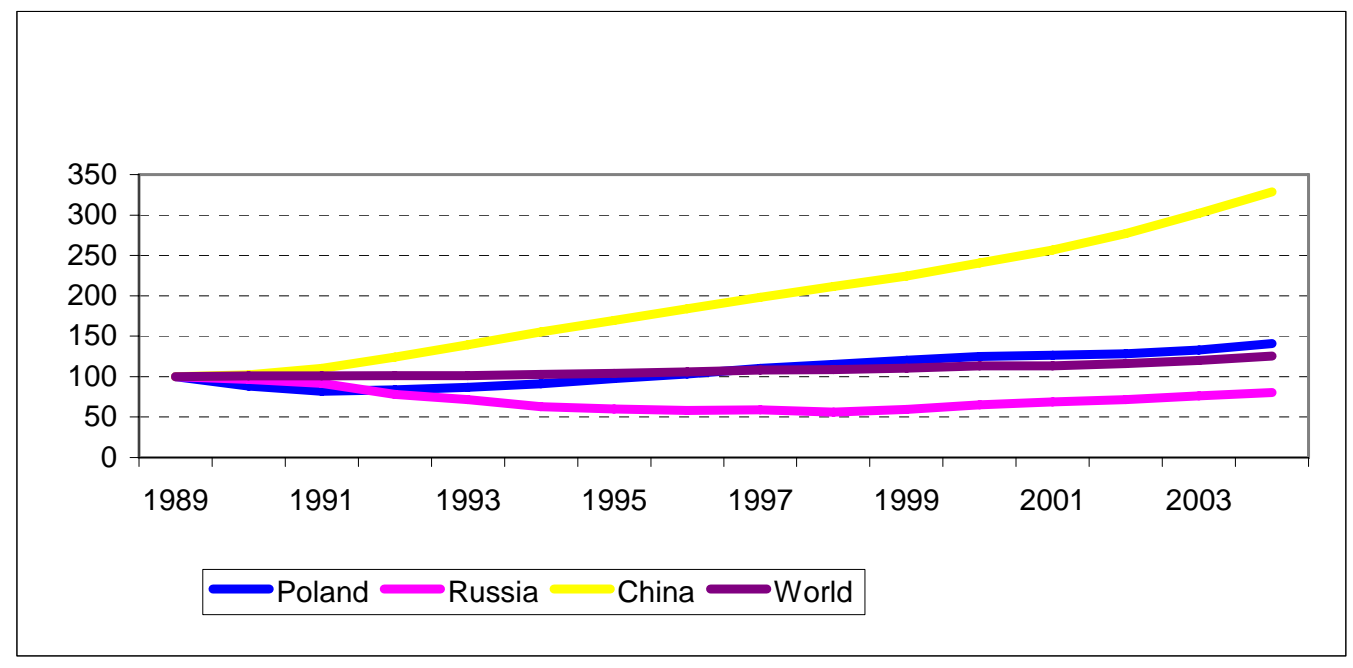

Note: $1989=100$.

Source: World Bank (2004).

Of course, the period of fundamental systemic changes related to the very essence of the post-socialist transformation has its specificity. It has involved many processes and phenomena which were extremely difficult to predict and accurately forecast. This may explain, but only to some extent, the enormous gap between the highly optimistic declarations and expectations on the one hand and reality on the other. Regrettably, this phenomenon has not as yet been studied in detail, but one can assume, not only on intuitive basis, that the societies of Central Eastern European and post-Soviet countries expected to achieve, after a decade and a half of transformation, twice as high a national income as they actually recorded-roughly equivalent, on average, to its level of 1989.8 This leads to the question about the error margin in today's assumptions. Do the 'elites'

8 See EBRD (2003). 
and societies still expect more (and how much more?) economic growth in the next 15 years than they will actually manage to accomplish? Surely, we still see excessive optimism, especially in countries integrating or striving to integrate with the European Union, but much more realism is being observed, too. One learns from experience.

\section{The foundations of growth}

Any attempt to answer the question about the sources of much-needed growth at the current phase of structural transformation should take into account two main factors. The first is a steady improvement of allocative efficiency, resulting from better utilization of resources (in comparison with the period preceding the transformation and its early stage, marked by a lot of friction). This requires constant efforts to stimulate creative enterprise, appropriate resource utilization at microeconomic level, and measures to improve the quality of corporate governance.

Figure 2: The rate of GDP growth/fall and unemployment rate in Poland (1990-2007)

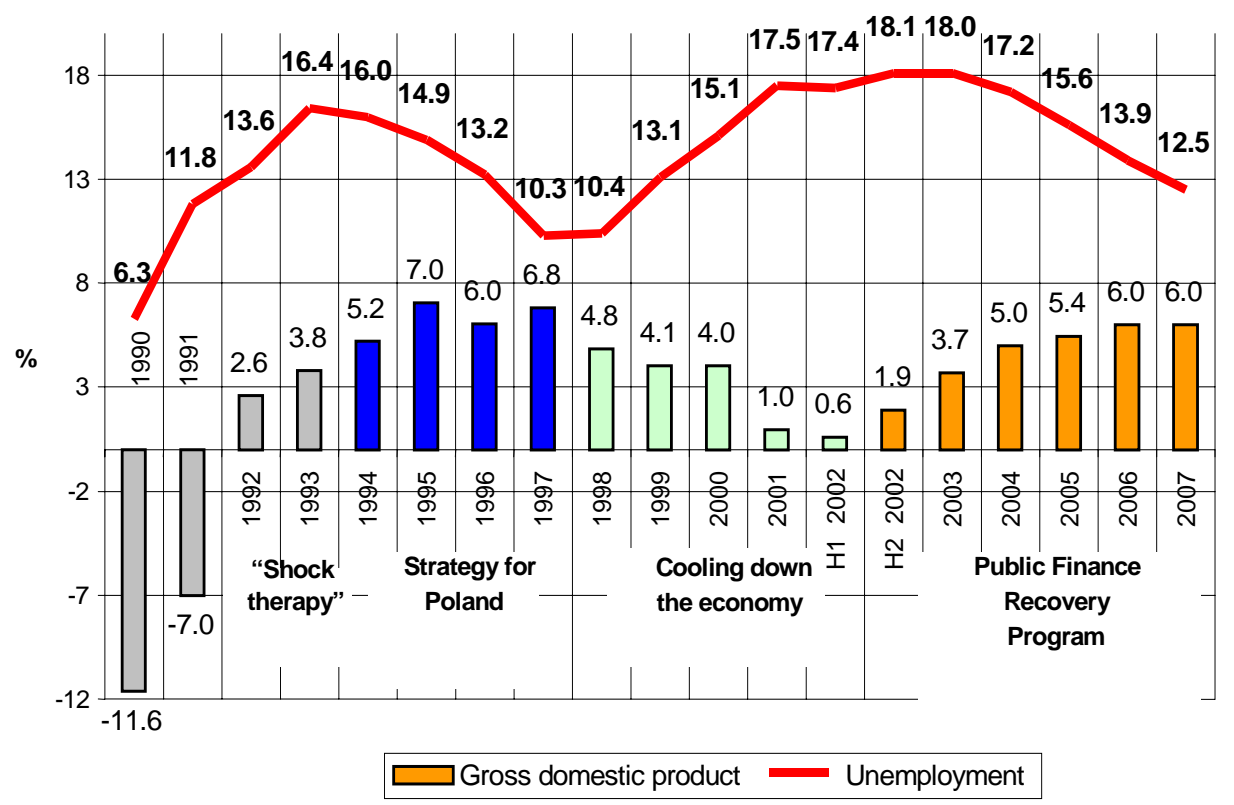

Note: The indicators shown above are based on the old methodology of unemployment calculation, which underestimates the results by about 2 percentage points in comparison with the current method.

Source: 1990-2003, Central Statistical Office (GUS); 2004-07 projection, after PNFR (2003).

Poland has achieved a great deal in this field and continues to make progress, as shown by the constant increase of labour productivity (Figure 2). In recent years-since 1998, when strong budgetary and monetary measures were taken to cool down the economyit has been the only source of output growth. For output has been increasing all the time, although at varying rates, accompanied by decreasing employment figures and concomitant growth in unemployment. Opposite tendencies emerged only for brief spells, especially in 2003, when unemployment began to decrease thanks to the one-off 
intervention consisting in the cancellation of debts owed by more than 60,000 small and medium-size enterprises, and GDP dynamics increased significantly from 0.8 per cent in the second quarter of 2002 to 3.8 per cent a year later.9 Then, unfortunately, unemployment rose again by more than one percentage point and reached, following a different calculation method than before, 20.6 per cent in February 2004. This is one of the differences between transition economies in the midst of profound structural and institutional changes and highly developed economies. In the latter, a GDP growth rate of just 1-2 per cent is enough to stimulate employment and reduce joblessness, whereas in our region, without special anti-unemployment measures (an area where not enough proactive steps are taken despite the repeated political declarations), employment does not begin to go up until GDP growth approaches 4 per cent.

Incidentally, this 'side effect' of the hitherto transformation efforts-massive unemployment afflicting Poland—is by far the most harmful outcome of the misguided economic policy: the overshot stabilization programme at the beginning of the previous decade and the overcooling of the economy towards its end. The inept 'proactive' antiunemployment policy in the past few years is also to blame. Surely, the market transformation would hardly have gained the approval of the public, had it been announced fifteen years ago that after nearly generation-long endeavours, almost one in every five of us would be out of job and frequently-which is the most distressing thing-without prospects of finding one. This is inevitably a frustrating situation, bearing in mind that long-term unemployment is the main cause of poverty. As much as 69 per cent of the population of the EU accession countries believe unemployment to be the main factor responsible for poverty and social exclusion, whereas in the 'old' EU states this indicator stands at 50 per cent. 10

The other growth factor is a renewed, after a period of sharp decline caused by the transformational shock and recession, propensity to save and to accumulate capital (Figure 3). An increased accumulation capacity in the economy is necessary in the long run to maintain a high growth dynamics, especially in a situation when many simple reserves opened up by the new economic system are exhausted as the transformation proceeds. It is necessary not only to encourage domestic savings, but also to attract-in the open economic environment-foreign savings in the form of portfolio capital and, especially, foreign direct investment. These create a new production capacity which often boosts the competitiveness of the economy and its export potential, thus facilitating export-driven economic growth. Of course, this form of expansion depends even more crucially on other factors, especially the rates of exchange and trade policy in all its aspects, but the role of foreign direct investment as a significant factor in the formation of capital and modern production capacity must not be overlooked. The fact that we expect nowadays an increased propensity to save does not imply that this

\footnotetext{
9 See Kolodko (2003).

10 See European Commission (2004a).
} 
indicator was low under the previous system. Far from it, it was very high indeed, at times even excessive. Planned economy was characterized by a very high rate of accumulation and investment, except that these resulted from forced saving, in contrast with the mechanisms of voluntary saving triggered by market economy. Savings were made then, partly due to necessity faced by insufficient supply in a shortage economy. Today Poland's citizens choose to save, where possible, for the future. However, the transition from planned to market economy should not be equated with an increased propensity to save combined with a lower marginal propensity to consume in the long run. What is needed nowadays, in a developing market environment, is increased efficiency in the use of whatever savings we are able to make on the nationwide scale.

Figure 3: GDP growth in Poland in subsequent four-year periods, 1990-2001

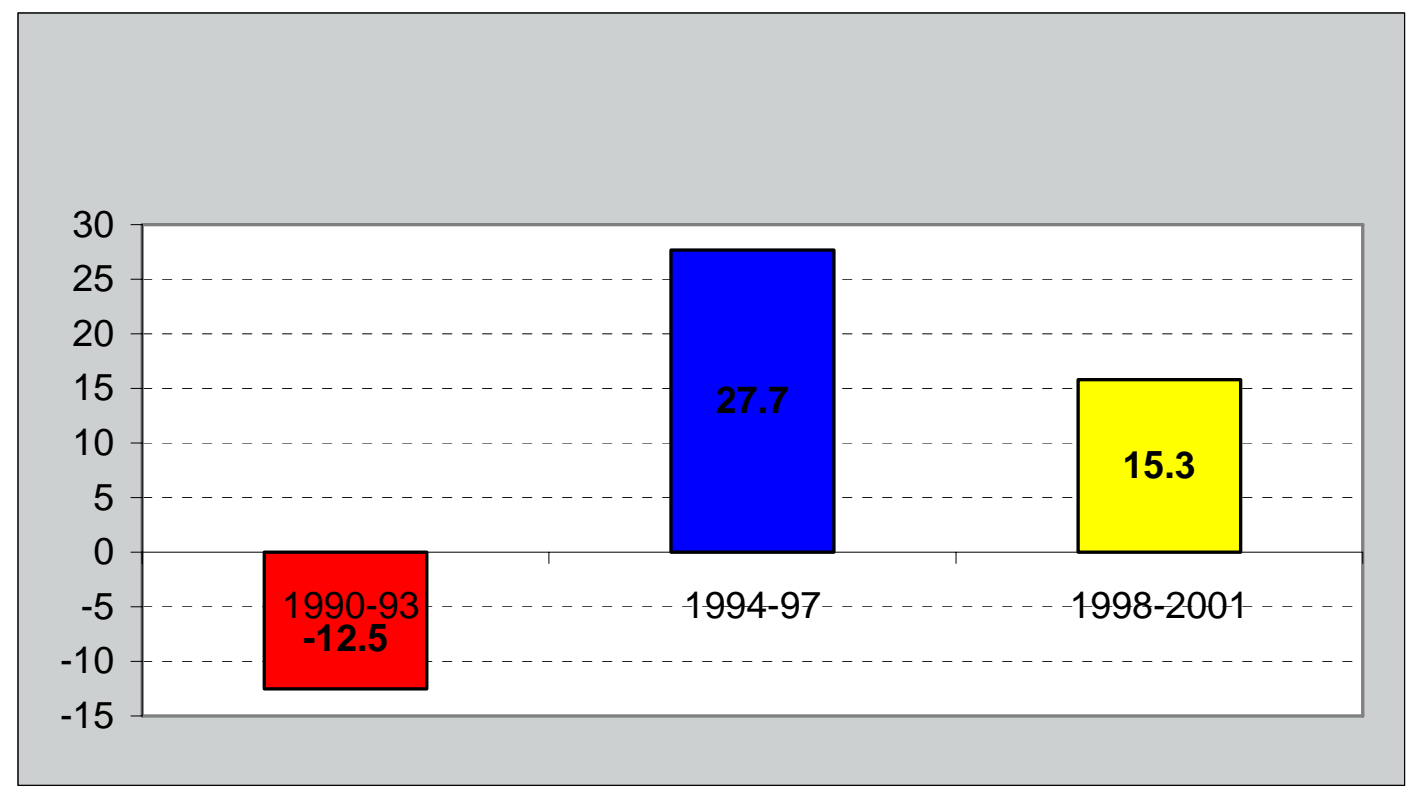

Source: Central Statistical Office (GUS), Warszawa.

Over the last decade and a half, we should have learned something in this respect. At times when economic policy_-both at macro level, oriented towards stimulating savings and controlling macro-scale growth proportions, and at micro level, stimulating improvement in corporate governance and competitiveness-was essentially correct, growth rate was markedly higher. Similar opportunities (and threats) will also exist in the future. Today no one is in a position to plot even an approximate GDP growth curve in Poland until, say, 2030. Whatever its shape, however, this curve will periodically depart, alternately upwards and downwards, from an averaged trend line-if for no other reason then because of the fluctuations typical of the business cycle. But whether this average growth rate will be closer to 6 per cent, which would be a great success, or to a mere 3 per cent, which would be a failure, will depend on the quality of development policy. In the recent past, when a better policy was followed, GDP growth was likewise higher, and vice versa. 
In the long run, the allocative efficiency of the capital employed should continually increase, whereas the rate of capital formation may and should increase only within the limits set by the consumption barrier. Therefore, within the time span of a couple of years, certainly not more than a decade or two, the only available way to increase growth will be to improve efficiency, without increasing in any way the relative burden imposed on the national income by accumulation, that is, without further increasing the share of investment in absorbed GDP. Only then we will have entered the phase of truly intensive growth (to borrow terminology from a different era), in contrast with extensive growth, which still prevails.

\section{$5 \quad$ Institution building and learning}

Both the collapse in the early 1990s and the great transitional depression that followed proved beyond any doubt that the one-sided orientation towards liberalization (of prices, trade, business entry and exit) and privatization, neglecting the importance of institution building - that is the rules of the market economy game-for the efficient functioning and development of market economy, came at a heavy price for all (well, nearly all) of us. Such a recipe is certainly not sufficient to create a dynamic, expanding market economy. 11 Worse still, lost output is unrecoverable, while social costs in terms of massive unemployment and exclusion are enormous.

Today, however, no one calls into question the role of institutions any more; just the opposite-it has been heavily emphasized for the last couple of years, even by the former advocates of a naive, neoliberal approach subscribing to the unrealistic notion that the mythical invisible hand of the market would now replace the old institutions, which were rightly being eliminated, such as state ownership, central planning, administrative controls on prices, inconvertible currency or subsidies. In most cases it is not that simple: the old institutions must indeed be dismantled or die away, but new ones must emerge in their place. The latter is a tedious process, requiring constant involvement of the state-itself one of the most essential institutions in the process of fundamental change. 12

The popularity of the term institutions towards the end of the first 15 years of transformation is comparable to that of liberalization and stabilization at the beginning of this period, or other buzzwords, such as privatization and deregulation slightly later. Nowadays, terms such as institutions, institution building, institutional structure of the market or institutional order are household words in many languages, not only English, but also Russian or Chinese. Luckily, in Polish, too. A review of the relevant literature worldwide, including the weighty publications of such institutions as the World Bank or, especially, the International Monetary Fund, would reveal a striking contrast

\footnotetext{
11 See North (1997).

12 See Kolodko (2000a); Kornai (2001).
} 
between the absence of these notions from earlier works, published in the early 1990s, and their very frequent use nowadays. 13

What, then, are institutions? In a narrower sense, institutions comprise the rules of the economic game-in this case, the market game-made up by the law and organizations that enforce compliance with these rules on the part of all economic entities, using incentives, rewards and penalties (carrots and sticks). The quantifier all used in this context includes the government and non-governmental organizations, enterprises from the vanishing state sector and expanding private sector, internal and external agencies operating in an open market economy, financial and capital-market intermediaries, as well as households. Incidentally, it should be noted that some confusion arises due to the fact that the word 'institution' is quite often used in the economic jargon in the sense of an organization or structure-one speaks, for instance, of financial institutions or state institutions-whereas the institutions that we discuss here organize, control and shape economic processes to ensure their sufficiently smooth progress, with due respect to the interests of all the partners in the social reproduction process. Just like traffic regulations, which govern the use of public roads, apply to pedestrians, drivers and the police alike, to streets and parking spaces, by day and by night. A car or scooter may be privately owned, but its use, in view of its external effects, is a matter of not only personal, but also public concern. Therefore, it must be subjected to some restrictions and regulated in ways the actors understand and are obliged to respect in the public interest, as well as for their own good. To continue this simile, institutions include both a speed limit and a ticket for breaking this limit, as well as a delinquency fee for its late payment; likewise, institutions comprise traffic regulations and the applicable enforcement measures.

By the same token, market institutions include both a contract between entrepreneurs and arbitration or court proceedings; both the price of a commodity or service, agreed upon between the buyer and the vendor, and the right to make a complaint about a faulty product, as well as consumer organizations which strengthen the market position of buyers vis-à-vis manufacturers and vendors. To sum up, institutions comprise:

1. the procedures and rules of conduct sanctioned by the law or by custom;

2. the applicable laws and regulations, promulgated in order to protect the interests of market entities;

3. the organizations and administrative/political structures that serve the needs of various market entities - from the government and central bank to capital-market agencies and anti-monopoly authorities (expected to compel economic entities to follow specific norms defined by the applicable laws in the interest of the entire socioeconomic system) to commercial banks and commodity exchanges;

4. lastly to extend the scope of our definition, institutions in the broad sense of the term also include market culture and mentality. In this perspective, institutions are not

13 See World Bank (2002); IMF (2003). 
only built, promulgated or decreed, but also understood and learnt. Besides, it is (or should be) obvious that this learning process, even if very actively pursued, must be gradual and lengthy. Also in the case of the unique, unprecedented process of reunification of Germany, the fourth institutional dimension, 'learning the market', had to be protracted and could not follow a shock formula, because no single political act would have effected a radical transformation of a culture and mentality rooted in the socialist system and planned economy into their capitalist, marketbased counterparts.

To be able to follow the rules of the market game, one needs an adequate knowledge, which may not always be acquired from textbooks or from other actors, but must be learnt by experience. One also has to form specific habits and characteristics, which were often unnecessary or poorly developed under the previous system. Now the old habits-so to speak, the 'old, non-market culture'-becomes a liability of which one has to be freed, in particular, by successively learning market economy. It is an instance of learning by doing, which takes time. It is thus a lasting process which, however, requires much less time to complete in those countries where market reforms had reached an advanced stage already by 1989 in comparison with those which embarked on a systemic transformation with institutions that followed more closely the socialist orthodoxy. This explains to some extent why the transitional recession was much shorter in Poland and Hungary than, for example, in Romania and Ukraine. I believe we still tend to underrate the cultural component of institution building and its importance for growth processes, while hastily assuming that adjustment in this field proceeds fast enough. Unfortunately, it does not.

In 1871, by Lake Tanganyika in Burundi, Sir Henry Stanley uttered the famous line 'Dr Livingstone, I presume?' on meeting another great explorer of the mysteries of Africa. Stanley was accompanied on his expedition by a group of native bearers. After a rest period, he ordered them to rise and get on the way, but the men were reluctant. When Stanley urged them to hurry they replied, 'We indeed hurry, but our souls can't catch up with us, so we need to wait for them a little longer'. Our attitudes are similar. We have to be goaded into action, and on the other hand, still need to wait for our souls to catch up.

It thus turns out that the changes of mentality in response to the challenges of systemic transformation - which is not restricted to the economic sphere, but also has its political, social and cultural dimensions - come about slowly. Intellectuals and enlightened economists, as well as forward-thinking political leaders (who like to solve rather than create problems), want these changes to be instituted as soon as possible in the newly emerging economic order and its actors, including economic entities and people who need to follow the new rules in the face of hard budget constraints and tough global competition. But these actors are like the souls of Stanley's bearers. They walk, or rather linger, behind their more knowledgeable guides, who are supposed to be able to 
find their way in the terra incognita of an emerging market economy and to persevere in pursuit of successive targets in the never-ending journey. After some delay, these new arrangements become accommodated by broader social groups which, like Stanley's men, are not exactly the vanguard on this difficult mission to chart the future, penetrate it in depth and, perhaps, find there a better world. Instead, they hamper the badly needed progress en route. Everything takes time to ripen and needs to reach maturity at its own pace and time.

As early as the mid 1990s, Anders Åslund (1995) concluded that Russia had already become a market economy, except that the people failed to understand it. To which I replied (and I still subscribe to this view) that if the people fail to grasp the nature and mechanisms of market economy with sufficient clarity and, therefore, disapprove of the current policy-applauded though it may be by technocratically-minded economiststhen this is hardly a market economy yet: just an economy in the process of market transition. In this sense, the systemic transformation is still under way in Poland and other countries of the region, although we have already joined the European Union, because the EU applies different assessment criteria and may have viewed our progress on the way towards market economy with excessive optimism. Such delays-partly organizational and partly cultural, or more broadly, civilizational in nature, hindering the attainment of a 'critical mass' by the market culture, which is a sine qua non of rapid growth-are a liability. Apart from the paucity of hard infrastructure and financial capital, they are the main factor limiting the pace of economic growth. To a large extent, these delays account for the existence and size of the gap between the theoretically attainable growth rate and the actual development path. However, if this is indeed the case, which it is, it should be seen as a manifestation of an excessively optimistic assessment of the actual potential to achieve a high growth rate under given institutional circumstances.

A policy will fail to put the existing social, human, financial and fixed capital to a better use, when institutional capital is in short supply. Therefore, a dual approach is needed. On the one hand, we should endeavour at all times to keep the evolution of institutions on the desired path — which includes their set-up, structure, maturation and learningwhile, on the other hand, we need to wait patiently 'for the souls to mature', facilitating this process in the meantime by sensible persuasion, so as to keep pressing ahead. No amount of rushing people to move faster and (political) lambasting will do any good. Worse still, such measures may provoke an increasing opposition against the direction and pace of change, thus fomenting protest and strengthening the propensity to rebel. This is what we observe these days in all post-socialist transition economies, even though the scale of these developments understandably differs across countries.

It is quite obvious that the institutional form of the Polish economy has been determined in general outline by the strategic orientation towards integration with the European Union. Our institutions will thus become gradually assimilated to those of the EU, 
reproducing in the process all the faults of the latter's institutional structure. Many of these are revealed by a comparison with the more efficient and more highly competitive institutional infrastructure of the US economy. For it appears that the US economy owes its higher production and consumption levels and markedly faster growth in the last decade mainly to the higher efficiency of its institutions, rather than to a superior national economic policy. American institutions are less bureaucratic than their EU counterparts, and so they provide a more favourable environment for business development and increased competitiveness of enterprises. This leads to some conclusions on how the EU should modify its institutions and policies-now also applicable to Poland as an EU member state.

\section{Better off, worse off?}

The social reception of the economic benefits accruing to the systemic transformation and the economic growth that has accompanied it for some time-since mid 1992 in Poland, but only since 1999 in Ukraine-has been cautious at best.14 Large sectors of society in post-socialist countries have been less optimistic, or more pessimistic, in their assessment of reality then their so-called political elites, including publicly involved, opinion-making economists.

Figure 4: 'Life satisfaction' in post-socialist countries joining the European Union

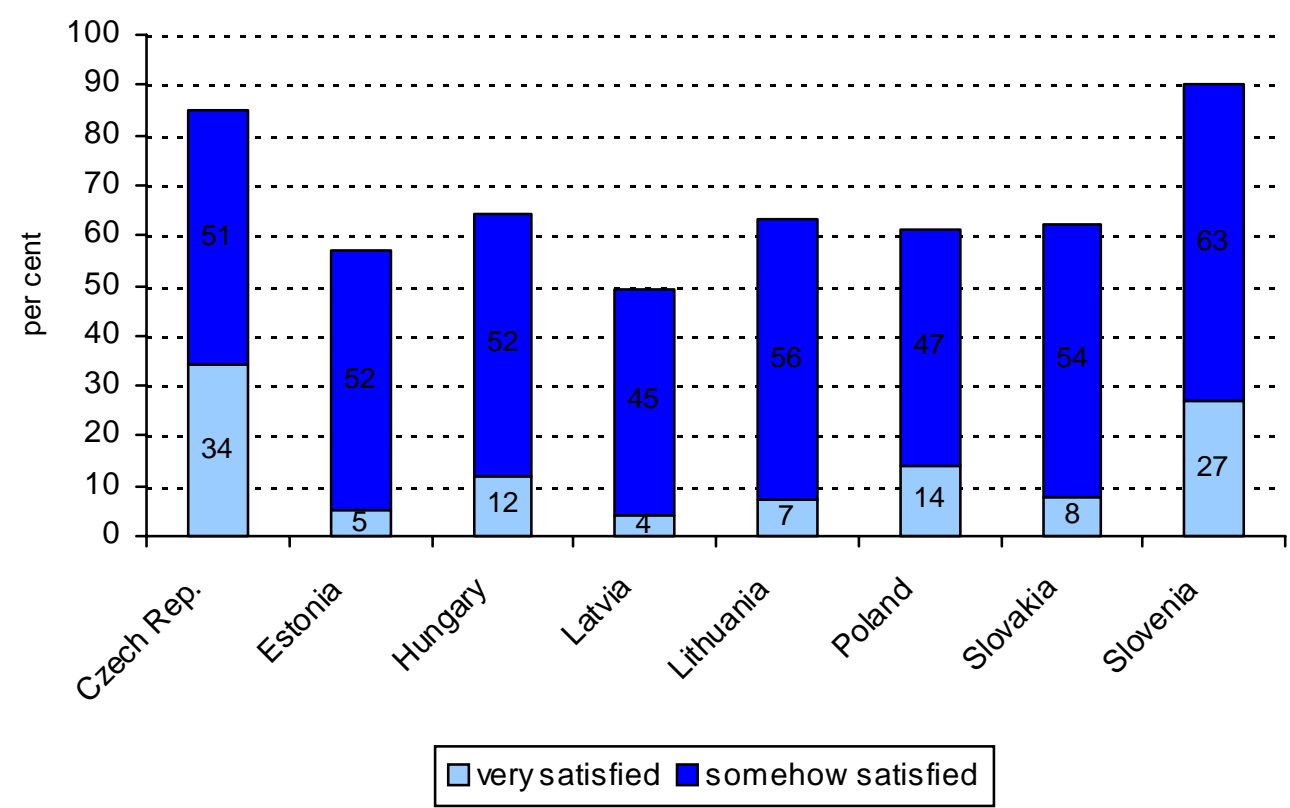

Source: European Commission (2004a).

The comparison of the quality of life as perceived by society in various countries and the corresponding satisfaction (or dissatisfaction) levels yields fascinating results. Taking into account nine dimensions—home, family life, neighbourhood, health, social

14 European Commission (2004a). 
life, personal security, work, income, and health service-it turns out that among the incumbent EU members (EU-15), the highest satisfaction levels are observed in Denmark and Austria, respectively, at 91 per cent and 89 per cent. The least satisfied with the quality of their lives are the inhabitants of Italy (72 per cent) and Portugal (71 per cent). The most significant factors in these assessments are satisfaction with home, family and social life, and the neighbourhood. Among the new EU-members (EU-10), the most satisfied societies are those of Slovenia (81 per cent)—surpassing several incumbents: Great Britain, Germany, Spain, Italy and Portugal-and the Czech Republic (70 per cent).

Closing the ranking list are Lithuania (59 per cent) and Latvia (55 per cent). Interestingly, Poland scores right behind Slovenia and the Czech Republic with a satisfaction level of 64 per cent (Figure 4). In post-socialist transforming countries, the relatively lower satisfaction level has to do with strictly economic factors-such as working conditions, earnings and access to medical services-which has some implications for the long-term development policy. In Poland, the average indicator of 64 per cent reflects the relatively high levels of satisfaction with family life, home and social life (respectively, 85 per cent, 84 per cent and 80 per cent) and limited contentment with work, earnings and the health system (respectively, 46 per cent, 33 per cent and 32 per cent). This is a striking asymmetry: the quality of life is lowest where the living standards are determined by politics and relatively high in those places where politics cannot essentially do too much harm, as people are generally left to themselves, their families, neighbours and friends. It follows - once again — that it is necessary and worthwhile to foster rapid economic growth, since this area leaves the most room for improvement.

It is both interesting and sad that of all nations of the enlarged European Union (EU-25), the Poles, when asked about the causes of their difficult situation, are the most likely to mention social injustice. As much as 53 per cent of the Poles blame on it their difficult material and social situation, as compared with the EU-15 average of 35 per cent. The fewest complaints in this respect among EU-10 come from the Czechs (31 per cent) and among EU-15 from the Danes (13 per cent). Equally interesting, though not so much sad as baffling, is the fact that only 13 per cent of the Poles attribute their failures and difficult material situation to laziness and lack of will power, in contrast with the Portuguese, who are much more given to self-criticism (31 per cent). The only societies among EU-25 who show an even greater reserve in this respect are the Lithuanians (8 per cent) are the Estonians (10 per cent).

In this context, one should wonder how to apply the old maxim that every cloud has a silver lining. How do we turn dejected and pessimistic moods into yet another growth driver? If society perceives its situation as worse than a fair and impartial analysis of the economic and social indicators would suggest, it is all the more necessary to move forward even faster. Assuming this is possible-and studies on potentially attainable 
growth rates (Kolodko 2002; IMF 2003) indicate that indeed it is-it then becomes all the more worthwhile to subordinate the policy to this imperative. We already know that institutions are vital, but so is policy. It should also be obvious that even top quality institutions (which are still a long way off in our case) do not automatically guarantee a good policy. One should be able to make creative use of both. Countries which have managed to do this_-alas, few in numbers-have also advanced further than others in their development. Significant differences exist in development levels attained in the first years of the 21st century, also within the enlarged European Union and between the EU and other most highly developed countries of the world. Let us remember that per capita GDP in the United States now exceeds the EU-15 average by more than 40 per cent. Thus if per capita GDP in Poland amounts at present to some 38 per cent of the EU-15 average, this translates into a mere 27 per cent of the USA standard.

Figure 5: Per capita GDP, adjusted for purchasing power parity (in PPS units)

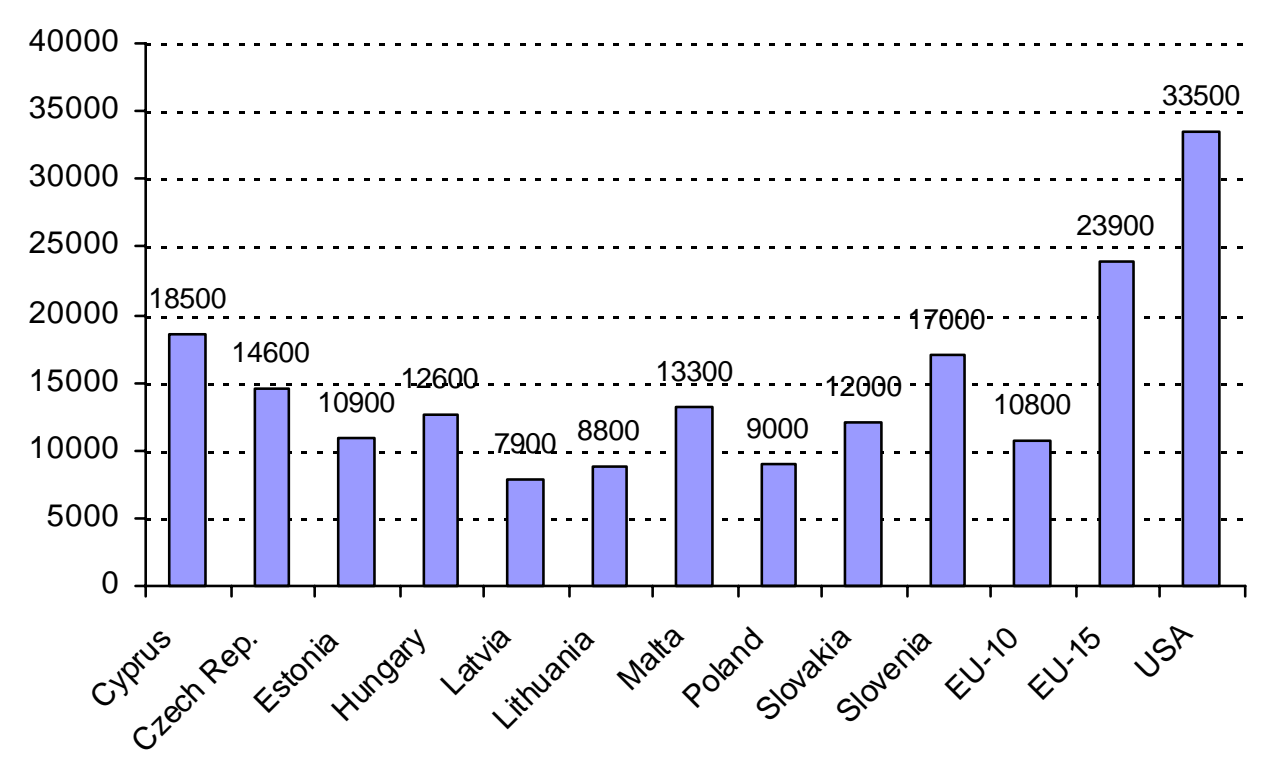

Note: The PPS (Purchasing Power Standard) is a unit representing an identical basket of goods and services in each of the countries being compared, regardless of price differentials. Approximately, 1 PPS equals 1 Euro. The estimates shown are for 2002.

Source: European Commission (2004b).

Given such an enormous gap in output levels and living standards between the new European Union members and rich countries, every fraction of a percentage point and every quarter of a year when GDP is even marginally higher matter on the scale of economic growth (Figure 5). After all, a long period is the sum of short episodes, and the output increments attained are the greater, in absolute terms, the higher the starting level was. Accordingly, the overshot stabilization programme and overcooling of the economy have not only cost us dearly in the past (Poland's current GDP is an estimated 20 per cent below what would have been attainable without those policy errors), but also encumber the future, just like the positive effects of faster growth in some past 
periods will continue to be felt in years to come. To see this, it is enough to realize that, starting from today's level of about US\$10,000 (in purchasing power parity terms), per capita GDP will have rise in 15 and 25 years, respectively, to US\$15,580 and US\$20,940 at an average growth rate of 3 per cent a year, US\$18,000 and US\$26,660 at 4 per cent, and as much as US\$20,790 and US\$33,860 if the economy expands by 5 per cent a year. If the growth rate fluctuates around the last-mentioned value for a time span of a whole generation, or about 25 years, even a difference of one per mille matters, as it translates into an extra US\$400 of income after a quarter of a century. The stakes, therefore, are high.

\section{The grey sector in politics}

As has been said, institutions are vital, and so is policy; institutions are not a substitute for it, but they facilitate or hamper its efficient implementation from the point of view of economic dynamics. We construe policy, in this context, in various ways, concentrating in most cases on its overt, public aspects. However, just like the economy has its grey sector (so-called shadow economy), hard to observe and control, so a grey sector exists in politics (shadow politics). It has been even less studied than its economic counterpart. The reason is that the scientific community and so-called independent media are all but paralyzed with fear when it comes to a systematic investigation of 'grey politics'. And yet many decisions, sometimes of key importance for economic growth, are taken in the grey sector and only then transferred to the sphere of overt policy at officially recorded cabinet meetings, sessions of the Parliament and its committees, or proceedings of the independent central bank and its monetary policy council.

The actual decisions are taken after informal discussions that take into account political arrangements and the position of various interest groups, whereas official politics serves only as a formal and public instrument to implement settlements made elsewhere. Elaborating on the simile between politics and economics, one can venture to say that the proportion of decisions made de facto in the political grey sector to those that are taken entirely through official channels is higher than the ratio of unrecorded and untaxed grey-sector turnover to registered economic transactions. Any analysis and evaluation of current policies should take into account this phenomenon, particularly in connection with recommendations on desired policy directions. It is fairly obvious that the scope for grey sector politics depends on the maturity of the institutions of a democratic state and civil society on the one hand, and the market economy on the other.

What, then, is economic policy? It should be seen as an ability to solve mass-scale social problems on economic grounds. To put it differently, it is a capacity to engage in a specific kind of game with all the actors involved in the liberalized market economy. In the context of the present discussion, it is a game which should lead to expanded macroeconomic reproduction. Its object is to maintain the highest growth rate possible 
and distribute its effects in an equitable, that is, socially acceptable, manner. For it is social sentiment, rather than the judgment of some economists or political leaders, that decides what is equitable and what is not. Ultimately, decisions on such matters must be taken in the parliament, through the adoption of laws, budget acts and other arrangements relating to the tax system, financial transfers, and social policy.

However, such public decisions are often secondary to decisions taken in private in government offices or party caucuses, since many persons involved view politics differently: as a matter of who supports whom against whom and for what kind of money. On such an interpretation, it is likewise a game, but one of a negative and often harmful character, oriented towards destroying political enemies and advancing particularistic interests of one's own and one's political clientele. In other words, politics, and especially the better part of grey-sector politics, does not have to be subordinated to the common good and public interest, and hence does not have to promote economic growth. Sometimes it may even impede it.

One might ask why the growth rate in Poland plunged form 7.5 per cent in the second quarter of 1997 to a stagnant 0.2 per cent in the fourth quarter of 2001. After all, it was hardly a consequence of external shocks. Neither was it a case of institutional retrogression, for the maturation process in this area went on uninterrupted. Privatization and liberalization were continued; openness to the global economy was increasing; integration with the European Union was in progress. But the state was being weakened and the economic policy was being misdirected through a harmful combination of liberal and populist ideas.

Furthermore, the power struggle aspect of politics is present at all times. Some attempt to stay in power, others to gain power, usually affecting in the process the dynamics of the economy by obstructing decisions that foster development and hindering growthpromoting structural reforms. In this approach to politics, the yardstick is the 'effectiveness' of a policy from the point of view of its proponents' interests, which translate in many cases into weakening authority, rather than enhancing growth tendencies. This inevitably leads to relatively slower growth, despite the successive strengthening of market institutions, mainly in the course of the ongoing adjustment of the Polish economy to the requirements of the acquis communautaire of the European Union.

\section{Assessments, warnings, suggestions}

The answer to the initial question about the origin of the gap between the potential (that is, supposedly attainable) and actual growth rate is thus at the same time trivial and penetrating: the discrepancy results from the shortcomings of the economic policy which purportedly could have been followed in the existing structural, institutional and cultural configuration. One might, therefore, ask 'if it could have been followed, why 
was it not?' But perhaps that very configuration not only hindered, but simply prevented the pursuit of a policy that would boost growth rate to its theoretical maximum? This is seemingly an easy question, especially in the context of two divergent and quite interesting opinions which are repeatedly voiced in the ongoing discourse.

On the one hand, the reviewers and critics of the actual policy—scholars, theorists, commentators, individual and institutional experts and advisors of all kinds, analysts, opposition politicians_claim as a rule that you can do better and achieve more. In particular, they point out that output volume and the scope of services provided could increase faster than they do in reality. On the other hand, those who implement this policy - the government, central administrative authorities in charge of the economy, the central bank, political supporters of the ruling coalition, regional and local administrators-believe faster growth to be out of reach for the time being and, if anything, only make predictions (bona fide or otherwise) of its increase in a longer or shorter perspective.

Whereas the passive commentators (reviewers and critics) generally agree that a different, faster (or potential, to stick to our terminology) growth path is available - at least until some of them switch roles and take charge of actually running the economic policy - the opinions of the active participants are divided. Some believe it is possible to attain higher growth dynamics already in a short-term perspective, while others disagree. Worst of all, members of the active group are usually unable to attain sufficient consensus (a full consensus is always out of the question) as to the recommended course and methods of action. Interestingly, this is observed in all countries, including those which boast the most modern and sophisticated economic structure and the most mature market institutions-among others, the United States (Stiglitz 2003). This time, however, it is not just a question of conflicting views (which, after all, vary even more widely among the passive critics, who invariably attack those in power, from the left, from the right, or sometimes also from commonsensical positions): the main problem is that the measures they take often lack co-ordination, while the compromises they reach are devoid of creative content. The very term 'economic policy' gives rise to numerous issues that require constant deliberation.

First, there is the question of policy, which, in order to yield good and beneficial results, needs to be based on a vision and yet free from illusions. Without a vision, a policy (or a politician) is incomplete, half-hearted and decidedly unconvincing. It is like a journey without a destination or like aimless rambling which, enjoyable though it may be at times, fails to lead from A to B, as a policy should. A long-term vision should be at the same time ambitious and realistic, acting as a signpost showing society the right development path and the way to fulfil its aspirations. It should stimulate such aspirations while keeping them within reasonable limits, so that they can in time be attained. If the lack of such a vision is covered up by the illusions of 'beneficial shocks' or 'civilizational leaps' in the sphere of declarations, and a foreshortened political 
perspective in the face of a coming election in actual practice, growth prospects are hardly encouraging.

Second, there is the question of economy — which means that the policy should be based on a theory that accounts for the workings of the economy and for its growth. A bad theory can only serve as a foundation of a bad policy. We have recently witnessed this in Poland, in the years of shock without therapy at the beginning of the previous decade and of needless cooling towards its end. By contrast, a good policy can only be formulated and pursued on the basis of a good economic theory, although such a theory is in itself not enough to accomplish this. But it certainly is indispensable.

There was a time when running the economy was far easier than today and one could, in a sense, get away with an uninformed economic policy, resorting to trial and error or in vivo experimentation. After all, a thousand years ago the world population amounted to just about 310 million. By now, however, mankind has become more than 20 times more numerous. The implementation of an economic policy-that is, exerting a deliberate and purposeful influence on participants in the economic market game in order to attain the goals of development: fuller satisfaction of society's needs as consumers thanks to more competitive enterprises, and an efficient state catering for individual and corporate actors-is nowadays an incredibly complex task which requires an enormous knowledge. Such a knowledge must be based not only on practical experience, but first and foremost on a good economic theory, which is, unfortunately, not always available. It is long since Michal Kalecki observed that, contrary to popular belief, politicians do listen to economists but only to those of the previous generation. Yet even modern generation economists have at their disposal only some elements of an economic theory, some empirical findings and fragmentary discussions. This situation is especially acutely felt under the conditions of the postsocialist transformation.

But the main problem is that economic views, all too often contradictory, are even more numerous than good ideas and could serve to pave many a road to hell. Politics, therefore, is constantly faced with dilemmas: whom to take heed of and whom to ignore? Which ideas to build upon and which to reject? Which to deem erroneous, and which correct? And how are we to know it, in the first place? Accordingly, the risk of errors is enormous and further aggravated by the fact that many politicians who pretend to be in the know are in fact ignorant, and even those who do have some knowledge often make mistakes anyway. For such is the peculiarity of economics that even those conversant with this discipline, to a greater or lesser degree, are still prone to error in policy decisions and choices. Moreover, the desire for dialog and compromise, flexibility and openness, justified though it is in many cases, is often confused with the need for methodological and factual correctness and academic rigor. Average values are useful in statistics, but not in development economics or growth theory. An efficient policy cannot be a result of 'averaging', with some elements taken from one scientific 
approach and some from another, mixing monetarism with a neo-Keynesian approach, new institutional economics with the Swedish school, socialism with capitalism - with a sole view to satisfying the possibly broadest spectrum of disputants.

Of particularly destructive character in our post-socialist realities are the attempts to combine leftist ideas in an intentionally social-democratic spirit with elements of neoliberal economics, taken out of the context of a theory which applies to the vastly different world of highly developed capitalism. 15 What is interesting, this tendency was equally pronounced in the coalition government formed by the Solidarity Electoral Action and Freedom Union (AWS-UW) in 1998-2001, and in that run by the Democratic Left Alliance and the Polish Peasant Party (SLD-PSL) in 2001-05. It was certainly a consequence of the fact that the policies of all these parties have been more often guided by their respective ideologies than by economic theory in the strict sense of the term. Regrettably, such a bizarre hybrid of left-wing populism and right-wing liberal market fundamentalism continues nowadays to weaken the economic fabric. It stands in the way of attaining the potential growth rate and, most important of all, prevents the painstakingly restored economic dynamics from being sustained in a long-term perspective.

Third, the abundance of views is matched by the multitude of interests at stake. The configuration of conflicting interests should be watched with even greater care than the meanders of theory, in order to find out why certain views, but not others, gain the upper hand. For in actual fact, it is differing interests, rather than views, that matter. In the end, some interests prevail, not some views. In this context, interests are primary and views secondary. The latter are often simply bought and sold, using a whole gamut of instruments of lobbying, political marketing, persuasion, pressure, or simply intellectual corruption. Under such circumstances, views are adjusted to fit the relevant pseudo-science (inspired de facto by political considerations and having very little to do with genuine learning).

In recent years, the best example has been provided by the lobbying in favour of a linear tax-an idea which is both theoretically erroneous and harmful in actual practice. It is intrinsically wrong in the context of both domestic capital formation, which it is ostensibly (but only seemingly) intended to foster, and does not provide for a socially advantageous redistribution of income. Incidentally, these two aspects are inseparable, as moving to a linear tax always entails a transfer of some net income from the poorer to the richer, which inevitably produces - in a society at an early phase of capital accumulation-a drop rather than an increase in the macro-scale propensity to save. This has been convincingly demonstrated by the past 15 years of transformation, when the increasing spread of incomes has usually been accompanied by a diminishing, and not growing, propensity to save. Such a transfer of income in the Polish conditions

15 See North (2002). 
would further markedly aggravate the trade imbalance by stimulating additional imports of costly, domestically unavailable goods and outward capital transfers. In the end, the national economy might be left with less rather than more resources. Such was the experience of Russia in recent years. Flat taxation is not only inequitable-which need not be a legitimate issue for every economist and politician-but first and foremost it has a destabilizing effect and destroys efficiency, which must not be overlooked by those economists and economic policymakers who are keen on ensuring sustained growth.

Fourth, the efficient implementation of good economic policy concepts requires determined political leadership. The decisionmakers must know what they want; we must really know 'what we are fighting for and where we are headed'. Without such knowledge, one gets stuck and treads water, which is not to say that those who are stuck and tread water do not struggle as hard as they can. But in that case even a good theory will not help, as there is a shortage of people who know how to use it. Correct answers are of little avail, either, if the political decisionmakers often do not even know what the questions are.

Political leadership can be analyzed at various levels. In a political democracy and a budding civil society, it is mainly the question of well organized, efficient political parties whose workings are open to public scrutiny, and of their leaders. From this point of view, the situation in Poland is highly inauspicious and, paradoxically, it is deteriorating instead of improving. This spells trouble for the future, not only from the point of view of potentially attainable growth rate. But even if the analyses and assessments were restricted to this single aspect, they would show clearly that the actual growth rate in the next couple of years, or perhaps even a decade or more, will be lower than potentially attainable without this extra-economic constraint. This is a factor which unlike, say, computers or oil, cannot be imported. It has to be learnt in the historic process of evolution and development, by building appropriate institutions and forging a new and different political culture.

Fifth, politics is the art of co-ordination. The multi-threaded nature of economic activity necessitates handling a great many matters simultaneously. Of course, some of them are more important or more urgent than others. Incidentally, the ability to find out what really is important and urgent and to tell fundamental and strategic issues from trivial everyday matters is a special gift that not all politicians possess. Politics, on the one hand, can be compared to managing a huge company or organization where multiple difficult decisions have to be taken at a moment's notice-sometimes in a crisis situation - often on the basis of incomplete information and under noisy pressure from the outside. On the other hand, it is a strategic activity which requires latitude, perspective and reflection. It also calls for a creative interaction with the less noisy parts of the environment-one's intellectual backers and experts, foreign partners representing the global economy, and, most importantly of all, social partners. If we 
succeed in achieving some measure of co-ordination among all these components, eliminating 'information noise' and friction in the decision-making mechanisms, the machine is working: decisions do not contradict one another, positive feedback channels are activated, obstacles that hamper the desired processes are removed and, in time, the expected results begin to show in the real and financial spheres, in respect of production, distribution and consumption. In short, the economy is growing.

Sixth and last, politics in all areas, including the economy, is the art of compromise. It is necessary at all times to keep searching for a creative consensus that reconciles the necessary with the possible, accommodates the contradictory interests of society in various time scales (as in the classic accumulation vs. consumption dilemma), resolves conflicts between short- and long-term interests of specific social, occupational and income groups, between the needs of the state and the regions, between taxpayers and the recipients of budget funds, between consumers and producers. There exist many more levels on which economic interests diverge. The point is that unless conflict-prone situations are defused using appropriate policy instruments, full-fledged conflicts threaten to develop. And then a compromise usually becomes even harder to reach. Moreover, a compromise needs to be positive, in the sense that-unlike a negative one, accepted out of necessity, but inconvenient to all parties - it should make everyone (or nearly everyone) satisfied to approximately the same degree with the settlement achieved. Such a compromise serves as a foundation on which one can try to build some reasonable long-term arrangements.

\section{Lessons from Poland's transition for emerging markets}

Unfortunately, too many compromises in Poland-covering issues from tax rates to the financing of highway construction to the calculation of old-age benefits-are makeshift, superficial and precarious affairs. This, far from balancing the dynamic socioeconomic relationships, prevents the economic policy from taking a more far-sighted perspective. A myopic, hand-to-mouth policy will never foster rapid growth: it is a task which requires a long-term approach. In Poland, unless the Public Finance Reform Programme16 is implemented in sufficient measure-which, most unfortunately, appears unlikely - a hand-to-mouth policy will continue to dominate. So far, this syndrome was overcome only once-and merely for a couple of years-in the course of the implementation of a long-term socioeconomic development programme linked with profound structural reforms and measures fostering market-economy institutions, known as The Strategy for Poland and pursued during 1994-97.17

It is thus possible to conduct a good economic policy under any structural, institutional and cultural circumstances, because the definition of a 'good' policy implicitly contains

16 PNFR (2003).

17 See Kolodko and Nuti (1997); Stiglitz (2002); Baka (2004). 
the assumption that it must fit the existing conditions-in a manner of speaking, it should be compatible with them. Of course, for the very same reason, a policy may be suboptimal or downright bad. History shows that the latter is, alas, far more frequent and, therefore, it is easier to quote numerous sorry outcomes, rather than spectacular successes, of economic policies. This is also true of post-socialist transforming economies, Poland included, particularly during certain periods in the past 15 years.

This explains why the attempts to transplant into the post-socialist realities a policy which may even have succeeded to some extent under different circumstances were doomed to failure-through the lack of compatibility. Such was the case with the adoption of recipes based on the so-called Washington Consensus in Poland and Russia in the early 1990s.18 Even if some political conception did work in practice, for instance, in Chile, it could have been totally inappropriate for Poland, and vice versa. Contrary to appearances, the reasons in both cases are not at all different, as they boil down in the end to the inadequacy of the proposed policy instruments for the existing institutions. It is like having a church organist play a virtuoso violin cadenza: it can be played, if only just barely, but hardly bears listening to. In this context we may even conclude - and the paradox here is only superficial—-that, for instance, Uganda has had a better economic policy in recent years than not only Zimbabwe, but also Germany. For a policy should never be assessed 'in the abstract', but only under concrete circumstances, here and now, and always in terms of its effectiveness.

Of course, the assertion that it is possible to conduct a better policy (more compatible with its determinants) in less favourable circumstances as well as a less appropriate one in a more advantageous environment should be seen as relative to the passage of time. That is to say that the external conditions should be seen as an objective given in a short time-span only; in the long run, the structural, institutional and cultural conditions for growth and development are created, shaped and modified by the policy itself. Being an object of policy, they provide feedback affecting its efficiency. And even if John Maynard Keynes (1924) was right saying that 'in the long run, we are all dead', before it happens, we have quite some time left to create and develop appropriate institutions by way of improving the law and bringing order to the rules of the competitive market game, to optimize the operation of the central and local government administration, and to promote the formation of non-governmental organizations that stimulate enterprise and the rise of a civil society. 19 This too is politics, except that it is conducted on a different time-scale and pertains to different matters.

Thus if our short-term policy is constrained by the existing institutional conditions, in the long run, we mould these institutions into a factor strongly promoting output growth and socioeconomic development. But such a policy calls for knowledge and skills of a

18 See Kolodko (1999); Stiglitz (1998).

19 World Bank (2004). 
different type than those required by the (admittedly difficult) tasks of adjusting tax and interest rates to encourage capital formation, applying the mechanisms of exchange rates and obligatory reserves to maintain a dynamic monetary equilibrium, or using public procurement and budget outlays as a means to improve the economic climate.

It appears then that Keynes was right-although not quite, because societies do not die even in the long-term perspective, development processes never cease, and as we have built upon the legacy of previous generations, it is only appropriate that we bequeath to our descendants something beyond mounting problems. And for the here and now, it may also be that those of us are right who believe that it is possible to attain economic success in the process and, moreover, know a thing or two about ways to achieve it.

\section{References}

Åslund, A. (1995). How Russia Became a Market Economy, The Brookings Institution: Washington DC.

Baka, W. (2004). 'Economic Ideas of the "Round Table” After Fifteen Years. Lessons for the Future', TIGER Research Papers 54, Transformation, Integration and Globalization Economic Research at the Leon Kozminski Academy of Entrepreneurship and Management: Warsaw.

EBRD (1996). Transition Report, European Bank for Reconstruction and Development: London.

EBRD (2003). Transition Report, European Bank for Reconstruction and Development: London.

European Commission (2004a). Perception of Living Conditions in an Enlarged Europe, European Foundation for the Improvement of Living and Working Conditions: Luxembourg and Dublin.

European Commission (2004b). Panorama of the European Union, European Commission: Brussels.

Helpman, E. (2004). The Mystery of Economic Growth, Belknap Press: Cambridge MA. IMF (2000). World Economic Outlook, International Monetary Fund: Washington DC.

IMF (2003). World Economic Outlook: Growth and Institutions, International Monetary Fund: Washington DC.

Keynes, J.M. (1924). A Tract on Monetary Reform, Macmillan: London.

Kolodko, G.W. (1993). 'From Recession to Growth in Post-Communist Economies', Communist and Post-Communist Studies 2(June): 123-43.

Kolodko, G.W. (1999). 'Ten Years of Postsocialist Transition: the Lessons for Policy Reforms’, Policy Research Working Papers 2095, World Bank: Washington DC. 
Kolodko, G.W. (2000a). From Shock to Therapy. Political Economy of Postsocialist Transformation, Oxford University Press for UNU-WIDER: Oxford and New York.

Kolodko, G.W. (2000b). Post-Communist Transition. The Thorny Road, University of Rochester Press: Rochester NY.

Kolodko, G.W. (2002). Globalization and Catching-up in Transition Economies, University of Rochester Press: Rochester NY.

Kolodko, G.W. (2003). Structural Reform and Economic Growth in 2002-2003. The Opening and Closing Balance, Transformation, Integration and Globalization Economic Research, Leon Kozminski Academy of Entrepreneurship and Management: Warsaw

Kolodko, G.W. (2004). The Polish Miracle. Lessons for the Emerging Markets, Ashgate: Aldershot.

Kolodko, G.W., and D.M. Nuti (1997). 'The Polish Alternative. Old Myths, Hard Facts and New Strategies in the Successful Transformation of the Polish Economy', Research for Action 33, UNU-WIDER: Helsinki.

Kornai, J. (2001). 'The Role of the State in a Post-socialist Economy', Distinguished Lectures 6, Leon Kozminski Academy of Entrepreneurship and Management: Warsaw.

Lin, J.Y., Fang C., and Zhou L. (2003). The China Miracle. Development Strategy and Economic Reform, Chinese University Press: Hong Kong.

North, D.C. (1997). 'The Contribution of the New Institutional Economics to an Understanding of the Transition Problem', WIDER Annual Lectures 1, UNUWIDER: Helsinki. Reprinted (2005) Wider Perspectives on Global Development, Palgrave Macmillan for UNU-WIDER: Basingstoke.

North, D.C. (2002). 'Understanding Economic Change and Economic Growth', Distinguished Lectures Series. 7, Leon Kozminski Academy of Entrepreneurship and Management: Warsaw.

PNFR (2003). Public Finance Recovery Programme, Rada Ministrów: Warsaw.

Podkaminer, L. (2004). 'Is Rapid, Long-Term Economic Growth in Poland Likely?', TIGER Working Papers 55, Transformation, Integration and Globalization Economic Research at the Leon Kozminski Academy of Entrepreneurship and Management: Warsaw.

Rodrik, D. (2005). 'Rethinking Growth Strategies', in Wider Perspectives on Global Development, Palgrave Macmillan for UNU-WIDER: Basingstoke.

Sachs, J.D. (2005). The End of Poverty: Economic Possibilities for our Time, Penguin Press: New York. 
Sen, A. (2000). Development as Freedom, Alfred A. Knopf: New York.

Stiglitz, J.E. (1998). 'More Instruments and Broader Goals: Moving towards the PostWashington Consensus', WIDER Annual Lectures 2, UNU-WIDER: Helsinki. Reprinted (2005) Wider Perspectives on Global Development, Palgrave Macmillan for UNU-WIDER: Basingstoke.

Stiglitz, J.E. (2002). Globalization and Its Discontents, W.W. Norton \& Company: New York and London.

Stiglitz, J.E. (2003). The Roaring Nineties. A New History of the World's Most Prosperous Decade, W.W. Norton \& Company: New York and London.

Tanzi, V., K.-Y. Chu, and S. Gupta (eds) (1999). Economic Policy and Equity, International Monetary Fund: Washington DC.

World Bank (2002). Building Institutions for Markets. World Development Report 2002, World Bank: Washington DC.

World Bank (2004). A Better Investment Climate for Everyone. World Development Report 2005, World Bank: Washington DC. 